\title{
OPTIMIZATION OF SUGARCANE HARVEST USING REMOTE SENSING
}

\author{
M. Rahimi Jamnani ${ }^{1}$, A. Liaghat ${ }^{2}$, F. Mirzaei ${ }^{3, *}$ \\ ${ }^{1}$ Graduate student of Irrigation and Drainage, Department of Irrigation and Reclamation Eng., College of Agriculture and Natural \\ Resources, University of Tehran, Karaj, Iran. mostafarahimi@ut.ac.ir \\ ${ }^{2}$ Department of Irrigation and Reclamation Eng., Faculty of Agriculture and Natural Resources of University of Tehran, Karaj, Iran. \\ aliaghat@ut.ac.ir \\ ${ }^{3}$ Department of Irrigation and Reclamation Eng., Faculty of Agriculture and Natural Resources of University of Tehran, Karaj, Iran. \\ fmirzaei@ut.ac.ir
}

KEY WORDS: Vegetation Indices, Sucrose juice, Pol percentage, NDVI, GNDVI

\begin{abstract}
:
In Iranian sugarcane agro-industries, the harvest time is estimated by sucrose content. Measuring the sucrose content in the juice (pol) during sugarcane harvest season will help users and farmers to achieve the best time for sugarcane harvest, which is important in accurate agricultural management. In harvest season, the pol percent is measured weekly by the destructive method through sampling of different areas of representative farms. In the this method, all fields are not sampled due to the plurality of fields and the need for expenditure and workforce, and the measured samples do not represent the entire area of a field. The aim of this paper is to find an optimal model for determine best harvest time for four sugarcane varieties using satellite vegetation indices, and also to obtain a zoning map which represents the areas ready for harvest during a harvest season in order to achieve maximum sucrose content. The results showed that, compared with NDVI and GVI, GNDVI represented higher correlation with pol $\left(\mathrm{R}^{2}=0.885\right)$. The optimum values of GNDVI were found to be between 0.5 and 0.55 , which indicated the areas with highest sucrose concentration. In addition, the zoning map was presented that makes it possible to separate spatially the areas ready for harvest in each field and they were also showed that central areas of farms ripened (reach maximum sugar content) sooner than sideways.
\end{abstract}

\section{INTRODUCTION}

\subsection{General Instructions}

Sugarcane (Saccharum officinarum 1.) is a perennial herb that grows in tropical and semi-tropical regions of the world between $37^{\circ} \mathrm{N}$ and $31^{\circ} \mathrm{S}$ latitudes. Sugarcane contains four distinct stages of growth namely sprout emergence, tillering, vegetative growth, and maturity (aging), each of which typically lasts one to three months.

The main economic attraction of sugarcane agro-industries is to produce large amounts of sugar and ethanol. (Nawi et al., 2013). Among sugarcane farm operations, harvest is very important and have high workload; the operators identify farms harvest time according to the amount of sucrose (Omrani, 2013).

Measuring the sucrose content in the juice (pol) during sugarcane harvest season will help users and farmers to identify the best time for sugarcane harvest, which is important in accurate agricultural management. Irrigation water is cut off in sugarcane fields after the vegetative stage, which increases sugar content in stems. Sugar content of sugarcane is declined after reaching a maximum amount due to environmental stresses and excessive drought. Therefore, the harvest time becomes important in order to achieve maximum sugar content. If the sugarcane is harvested early or late, productivity declines due to lower sugar levels. Eventually, the delay in sugarcane harvesting could reduce sugar production by 20 to $30 \%$ (Shomeili, 2012).

At the maturity stage, pol is measured by manual sampling. Pol is the apparent sucrose content expressed as a mass percent measured by the optical rotation of polarized light passing through a sugar solution (Valdrama et. al, 2007). Based on previous studies, the average cost of sugarcane harvest delay in Khuzestan province is estimated at 360 dollar per hectare daily (Omrani et al., 2013).

In a harvest season, the pol percent is measured weekly by the destructive method through sampling of different areas of representative farms. In this method, not all fields are sampled due to the plurality of fields and the need for expenditure and workforce. Moreover, the measured samples do not represent the entire area of a field. On the other hand, vegetation models provided for prediction sugarcane growth require agronomic and meteorological data, which are not readily available due to large spatial dispersion. The sugar industry, therefore, needs appropriate tools for a careful and documentable study on sugarcane cultivation to increase precision in monitoring and assessing sugarcane product and yield (Blaschke et al., 2010; Mulianga et al. 2012).

Various studies have reported methods that used near infrared spectroscopy to predict sucrose content of sugarcane juice (Tewari et al., 2003; Valderrama et al., 2007; Nawi et al., 2013; Ochola et al., 2015; Iskandar et al., 2016).

Nawi et al., (2013) focused on the field spectrometry of the cane stalk to estimate sugar yield. They analysed the reflection data with the brix index through regression analysis by partial least squares (PLS) and artificial neural network (ANN) model. the PLS model resulted in correlation of determination $\left(\mathrm{R}^{2}\right)$ value of 0.91 , and the accuracy obtained by ANN ranged between $50 \%$ and $100 \%$.

Ochala et al., 2015 were evaluated performance of a Matrix-F FT NIR spectrophotometer for estimation of cane quality in Nzoia Sugar Company, western Kenya. Pol and Brix were linearly regressed against the NIR results. The R2 values were

\footnotetext{
* Corresponding author
} 
$0.9787,0.9503,0.8432$ and 0.8725 for brix, pol, moisture and fiber, respectively.

Ishkandar et al., (2016) were utilized visible and shortwave near-infrared (VSWNIR) diffuse reflectance spectroscopy in combination with three classifier algorithm techniques in order to classify sugarcane Brix values. The results showed that the overall classification accuracies achieved by Bayesian discriminant analysis (BDA), support vector machine (SVM) and artificial neural network (ANN) were 77.8, 83.1 and 88.7\% respectively.

All above studies demonstrated that Near Infrared spectroscopic analysis is an acceptable and cost effective method for prediction, classification and assessment of sugarcane quality parameters. Recently, some studies have estimated sugarcane sucrose using different satellite vegetation indices.

In a research conducted by Bégué et al. (2010), SPOT 4 and SPOT 5 images were used to compare maximum NDVI and the areas under the curve of NDVI with field-scale yield values by considering an exponential relationship between them. Finally, the coefficient of determination $\left(\mathrm{R}^{2}\right)$ was obtained as 0.78 .

Zhao et al. (2016) conducted a research on sugarcane fields and showed that NDWI (Normalized Difference Water Index) could be used to estimate sugarcane pol percentage with a precision of 0.90. They further developed a model using calibration factors to estimate sugarcane yield.

Satellite vegetation indices have facilitated the exploration of spatial variables in heterogeneous lands (Mulianga et al., 2012). Vegetation indices obtained from satellite imagery during the growing season can be a suitable measure to monitoring of sugarcane farms status (Zhao et al., 2016).

The aim of this paper is to find an optimal model for determine best harvest time for four sugarcane varieties namely CP691062, CP48-103, CP73-21 and CP57-614 at Imam Khomeini Sugarcane Agro-industry with using satellite vegetation indices, also to obtain a zoning map which represents the areas ready for harvest during a harvest season in order to achieve maximum sucrose content.

\section{MATERIAL AND METHODS}

\subsection{Study Area}

Imam Khomeini Sugarcane Agro-Industry is located in Khuzestan Province, Iran (Figure 1). In summer the climate is hot and arid and in winter moderate and non-freezing, with an average annual precipitation of $237 \mathrm{~mm}$. In this area, Sugarcane is irrigated by the furrow irrigation system. This agro-industry is composed of 530 farms with a total area of 15,800 hectares. On average, 12,000 hectares of land is allocated to sugarcane each year. The varieties include CP69-1062, CP48-103, CP73-21 and CP57-614, representing 40, 30, 25 and 5 percentage of the study area, respectively.
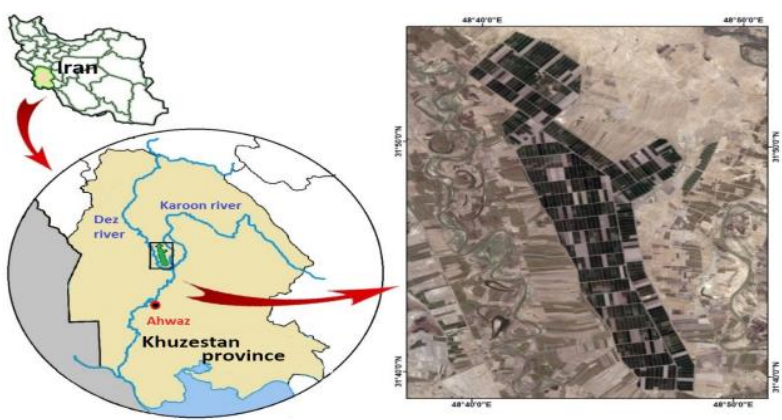

Figure 1. Location of Imam Khomeini Sugarcane Agro-industry

\subsection{Pol percentage sampling}

As shown in Figure 2, for each sugarcane variety, at least 10 representative farms were selected with about the same planting dates and environment conditions. According to the area of farms which are about 25 hectares, 5 samples were taken and the mean of the samples were obtained for each farm. the percentage of sucrose content in the juice (pol) was obtained from weekly sampling of farms at the aging stage during three season from 2014-2015 to 2016-2017.

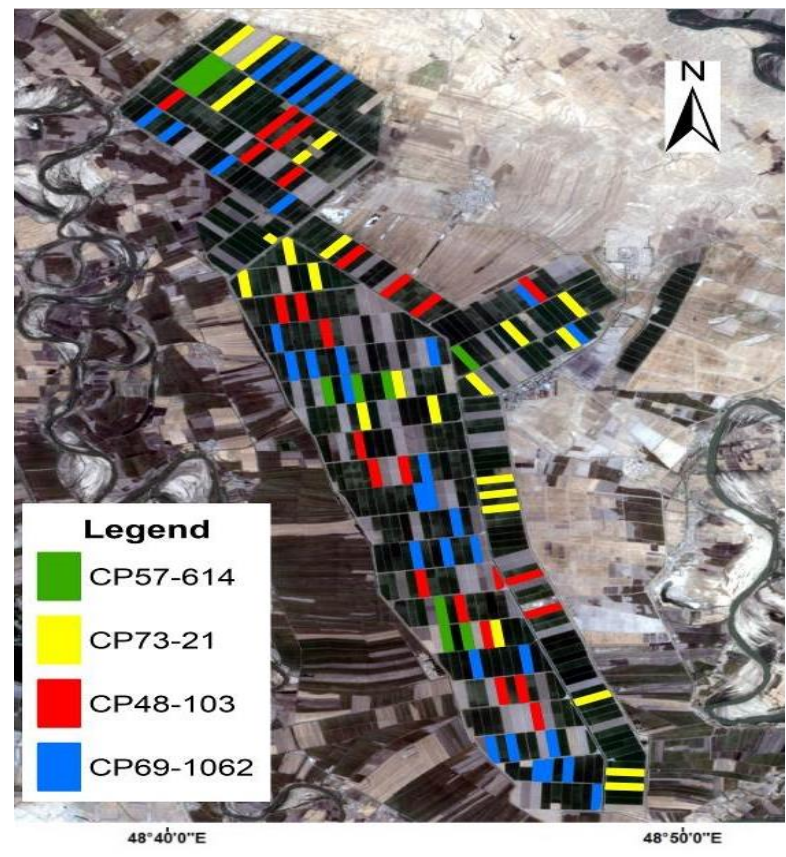

Figure 2. In this study, 36, 24, 20 and 10 farms were sampled for varieties CP69-1062, CP48-103, CP73-21 and CP57-614, respectively.

\subsection{Remote sensing data}

A total of 16 Landsat 8 OLI/TIRS images were used for three years. The images were selected according to the onset of sugarcane maturity stage in study area, which starts from midOctober and lasts until mid-February. Table. 1 lists the dates and codes of images in this research.

\begin{tabular}{|c|c|}
\hline Landsat 8 Images & Acquired Dates \\
\hline LC08_L1TP_165038_20141012 & $2014 / 10 / 12$ \\
\hline LC08_L1TP_165038_20141113 & $2014 / 11 / 13$ \\
\hline LC08_L1TP_166038_20141206 & $2014 / 12 / 06$ \\
\hline LC08_L1TP_165038_20141231 & $2014 / 12 / 31$ \\
\hline LC08_L1TP_166038_20150123 & $2015 / 01 / 23$ \\
\hline LC08_L1TP_165038_20151015 & $2015 / 10 / 15$ \\
\hline LC08_L1TP_165038_20151116 & $2015 / 11 / 16$ \\
\hline LC08_L1TP_166038_20151225 & $2015 / 12 / 25$ \\
\hline LC08_L1TP_165038_20160103 & $2016 / 01 / 03$ \\
\hline LC08_L1TP_166038_20160126 & $2016 / 01 / 26$ \\
\hline LC08_L1TP_165038_20160220 & $2016 / 02 / 20$ \\
\hline LC08_L1TP_165038_20161017 & $2016 / 10 / 17$ \\
\hline LC08_L1TP_165038_20161118 & $2016 / 11 / 18$ \\
\hline LC08_L1TP_166038_20161211 & $2016 / 12 / 11$ \\
\hline LC08_L1TP_166038_20170112 & $2017 / 01 / 12$ \\
\hline LC08_L1TP_165038_20170206 & $2017 / 02 / 06$ \\
\hline
\end{tabular}

Table 1. 16 Landsat 8 images used for calculating vegetation indices of farms. 
Numerous vegetation indices have been used to consider plant status. In the present research, three indices were used to estimate sugarcane yield, namely $\mathrm{NDVI}^{1}, \mathrm{GVI}^{2}$, and GNDVI ${ }^{3}$. NDVI is an index to measure health and greenness of plant. The combination of its normalized difference formulation and use of the highest absorption and reflectance regions of chlorophyll make it robust over a wide range of conditions. However, NDVI can be saturated in dense vegetation conditions when LAI becomes high (Rouse et al., 1973).

$$
N D V I=\frac{N I R-R E D}{N I R+R E D}
$$

where $\quad N I R=$ Near Infrared band of Landsat 8 $R E D=$ Red band of Landsat 8

NDVI takes values between -1 and 1 . Normally for sugarcane, this index has some value between 0.15 and 0.85 .

GVI refers to green vegetation index, which minimizes the effects of background soil and emphasizing green vegetation.

$$
\begin{aligned}
& G V I=(-0.2848 \times B A N D 1)+(-0.2435 \times B A N D 2) \\
& +(0.5436 \times B A N D 3)+(0.7243 \times B A N D 4) \\
& +(0.0840 \times B A N D 5)+(-0.0840 * B A N D 7)
\end{aligned}
$$

\section{where $\quad$ BAND1 to $7=$ Band 1 to 7 of Landsat 7 satellite}

Band numbers was originally designed to be used with LANDSAT 7 TM bands, but then it was used with corresponding bands on LANDSAT 8 (Kauth et. al, 1976). GDNVI is mostly similar to NDVI, except that here green spectrum (540-570 nm) is measured rather than red spectrum.

$$
G N D V I=\frac{N I R-G R E E N}{N I R+G R E E N}
$$

\section{where $\quad$ GREEN $=$ Green band of landsat 8}

The Level 1 Landsat images were calibrated radiometrically to obtain their top of atmosphere (TOA) reflectance. Vegetation indices of each field were obtained by average of pixel values in each fields. It should be noted that pixels containing the ridges of fields or those being part of bare soil or irrigation channel were excluded from the calculations.

\section{RESULTS}

\subsection{Pol measurements}

The pol is measured for representative farms through 20142015 to 2016-2017. Figure 2 shows the averages of measured pol in a single year. As shown in Figure 2, maximum pol percentage and the date of its occurrence varies for each variety. The best harvest time for varieties CP69-1062, CP48-103, CP73-21 and CP57-614 is in mid-January, late-January, earlyJanuary and mid-December respectively. The time to reach the maximum amount of sucrose depends on variety and planting date (last harvest date). The maximum pol also was found in variety CP73-21 on average (up to $19.9 \%$ ).

\footnotetext{
${ }^{1}$ Normalized Difference Vegetation Index

${ }^{2}$ Green Vegetation Index

${ }^{3}$ Green Normalized Difference Vegetation Index
}

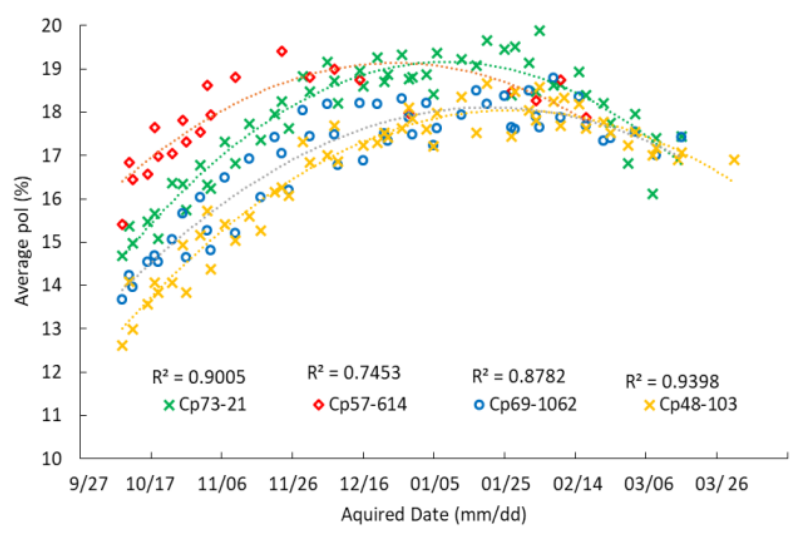

Figure 2. Average pol samples for four sugarcane varieties.

\subsection{Pol estimation using Vegetation indices}

The vegetation indices were calculated from Landsat 8 images for each sugarcane farm (Average pixels values). The correlation between the vegetation indices (GVI, GNDVI and NDVI) and sucrose content (pol) for each variety were obtained in Figure 3.
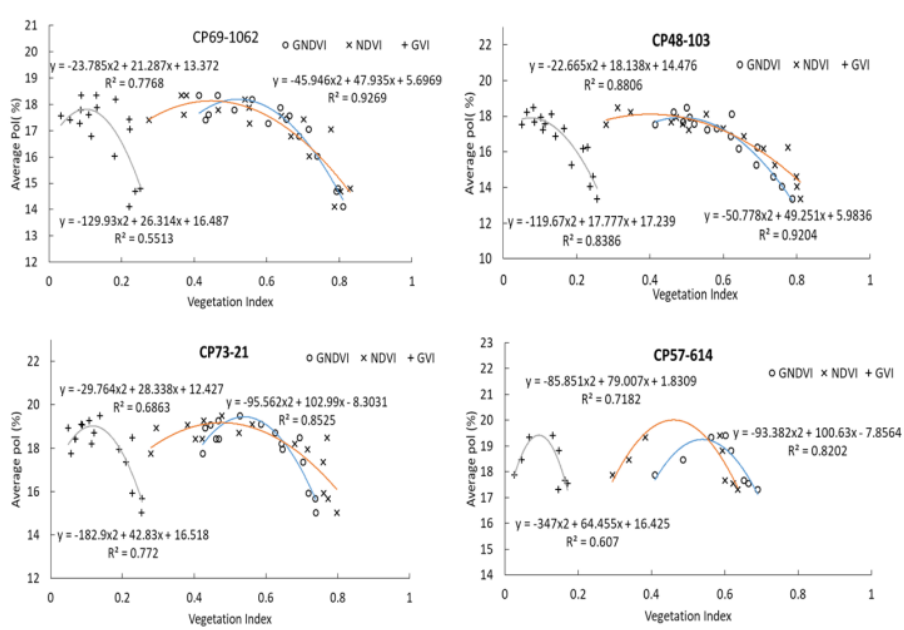

Figure 3. The correlation between the vegetation indices

(GNDVI) and pol for CP69-1062, CP48-103, CP73-21 and

CP57-614, respectively.

According to figure 3 , the coefficient of determination $\left(\mathrm{R}^{2}\right)$ of NDVI, GVI and GNDVI on average were defined $0.765,0.692$ and 0.885 respectively. The coefficient of determination $\left(\mathrm{R}^{2}\right)$ of NDVI was almost equal to those Begu et al. (2016) were estimated (0.78). The GNDVI and pol showed the highest correlation in overall. Numerous studies have shown that for dense crops with LAI more than 3, GNDVI performs better than NDVI due to pixel saturation (Benvenuti et al., 2010; Robson et al., 2012; Rahman et al., 2016).

The Quadratic equations were used to obtain appropriate GNDVI value corresponding to the maximum sucrose. Table 1 shows appropriate GNDVI value corresponding to the maximum percentage of sucrose, which derived from quadratic equation of each variety. 


\begin{tabular}{|c|c|c|}
\hline Variety & Quadratic Model & $\mathrm{GNDVI}^{*}$ \\
\hline $\mathrm{CP} 69-1069$ & $\mathrm{POL}=-45.95 * \mathrm{GNDVI}^{2}+47.93 * \mathrm{GNDVI}+5.70$ & 0.52 \\
\hline $\mathrm{CP} 48-103$ & $\mathrm{POL}=-50.78 * \mathrm{GNDVI}^{2}+49.25 * \mathrm{GNDVI}+5.98$ & 0.49 \\
\hline $\mathrm{CP} 73-21$ & $\mathrm{POL}=-95.56 * \mathrm{GNDVI}^{2}+102.99 * \mathrm{GNDVI}-8.30$ & 0.54 \\
\hline $\mathrm{CP} 57-614$ & $\mathrm{POL}=-93.38 * \mathrm{GNDVI}^{2}+100.63 * \mathrm{GNDVI}-7.86$ & 0.54 \\
\hline
\end{tabular}

Table 1. The Quadratic equation and appropriate GNDVI value of each variety

Since full harvest of a 25-hectare sugarcane field takes one to two days, the best harvest time is when the GNDVI is in the range from 0.50 to 0.55 at the maturity stage.

\subsection{Zoning map of sugarcane farms}

The zoning map of sugarcane farms obtained by classifying based on GNDVI during 2015-2016 harvest season. Based on the results, the classifications of $0-0.35,0.35-0.5,0.50-0.55$, and over 0.55 represent harvested, overdue harvest, ready for harvest, and not ready yet to harvest areas, respectively. Figure 4 shows an example of the five classified farms status in different dates in 2015-2016 harvest season.

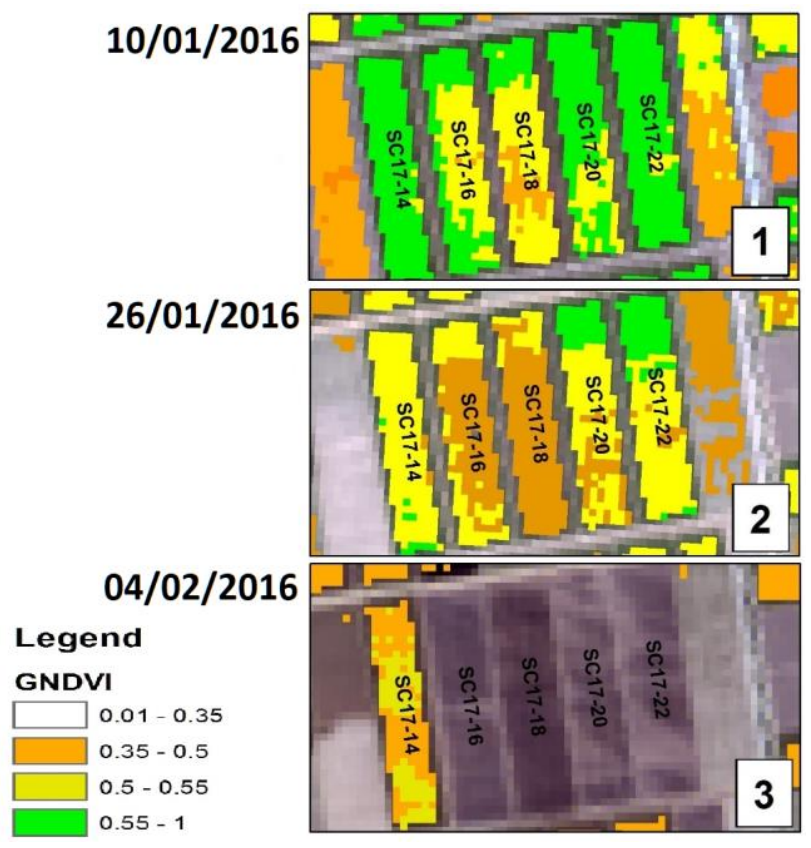

Figure 4. Farms classifications on different dates of 2016-2017 harvest season.

According to the Figure 4, on January 10, one farm out of the five was ready to harvest (SC17-18). On January 26, three of them were ready to harvest (SC17-14, SC17-20 and SC17-22), and two of them were far from optimal condition (SC17-16 and SC17-18). It can be seen on February 4, four farms out of five were harvested and SC17-14 was not still harvested.

Farm number SC17-16 and SC17-22 were harvested on January 31, SC17-18 and SC17-20 on February 3 and also SC17-14 on February 10. According to the model, however, the harvest times for farm number SC17-16 and SC17-18, were estimated on January 14, SC17-14 and SC17-20 on January 26, and SC17-22 on 17, respectively. According to the results, on average, the process of harvesting was delayed by 2 weeks during 2015-2016 harvest season.

As mentioned above, pol samples are taken only from representative fields, while the conditions are not the same in each field, and sugarcane plants throughout a single field do not contain a certain sucrose levels. The other problems that caused delays in harvesting included lack of equipment and machinery. (Omrani, 2013).

As it can be seen in Figure 4, the central areas of the fields have a drier soil than the margins due to drainage and no access to water leaked from the irrigation or drainage channels, hence losing water more rapidly and reaching maximum sugar content. The zoning maps in 2015-2016 harvest season showed that $44 \%$ of the farms were not harvested on time, and on average, $73 \%$ of them were harvested about two weeks later than optimal condition.

\subsection{Conclusion}

In this study, vegetation indices were used to model the pol values for different sugarcane varieties. Results showed that the time to reach the maximum amount of sucrose depends on variety and planting date (last harvest date). Among three vegetation indices (GVI, GNDVI and NDVI), GNDVI showed higher correlation with pol percentage $\left(R^{2}=0.885\right)$.

The GNDVI between 0.50 and 0.55 was obtained to find appropriate time to harvest sugarcane fields.

The zoning map indicated that farms harvesting were delayed by an average of two weeks.

The results also showed that the central areas of each farm reaches the maximum sugar sooner than sideways due to the proper drainage and having dryer soil.

The advantages of zoning map for harvest sugarcane unclude estimation of sugar content of each farm individually which is not possible with manual sampling and the ability to spatial separation of ready to harvest areas within each farm, which increases the productivity of the harvested sugarcane.

\section{ACKNOWLEDGEMENTS}

The authors hereby, would like to express gratitude to Imam Khomeini Sugarcane Agro-industry, which greatly assisted us in accomplishing the paper.

\section{REFERENCES}

Bégué, A., Lebourgeois, V., Bappel, E., Todoroff, P., Pellegrino, A., Baillarin, F., Siegmund, B. 2010. Spatiotemporal variability of sugarcane fields and recommendations for yield forecast using NDVI. International Journal of Remote Sensing. 2010, 31, 5391-5407.

Benvenuti, F. and Weill, M. 2010. Relationship between MultiSpectral Data and Sugarcane Crop Yield. Proceedings of the 19th World Congress of Soil Science and Soil Solutions for a Changing World, Brisbane, 33- 36.

Blaschke, M.T. 2010. Object based image analysis for remote sensing. ISPRS Journal of Photogrammetry Remote Sensing, $65,2-16$.

Ishkandar, C. D. M., Nawi, N., and Chen, G., Jensen, T., Mehdizadeh, S. A. 2016. Comparison of chemometrics methods for classification of sugarcane brix using visible and shortwave near-infrared technology. 3rd International 
Conference on Agricultural and Food Engineering (CAFEi 2016), Kuala Lumpur, Malaysia. 214-219.

Kauth, R.J. and Thomas, G.S. 1976. The Tasselled Cap-A Graphic Description of the Spectral-Temporal Development of Agricultural Crops as Seen By Landsat. LARS Symposium, 4B41-4B51.

Mulianga, B., Bégué, A., Simoes, M., Todoroff, P., Clouvel, P. 2012. MODIS data for forecasting sugarcane yield in Kenya through a zonal approach. In Proceedings of the Sentinel-2 Preparatory Symposium, Frascati, Italy, 23-27.

Nawi, N., Chen, G., Jensen, T., Mehdizadeh, S. 2013. Prediction and classification of sugar content of sugarcane based on skin scanning using visible and shortwave near infrared. Biosystems Engineering. 115. 154-161. 10.1016/j.biosystemseng.2013.03.005.

Ochola, P., Apunda, E. O., Yewa, E. O. 2015. Evaluation of Near Infrared Spectroscopy for Sugarcane Quality Determination in Western Kenya. Chemistry and Materials Research ISSN 2224- 3224, 7 (9), 30-37.

Omrani, A. 2013. Evaluation of Farm machinery management in sugarcane cultivation (case study Amir Kabir Agro-Industry). M. Sc. Thesis. Faculty of Agriculture. Shahid Chamran University of Ahvaz. (In Farsi). 16.

Omrani, A., Sheikhdavoodi, M. J., Shomeili, M. 2013. Determine Sugarcane harvester field efficiency using global positioning system (GPS) data. Elixir Agriculture, 56, 1326013263.

Puzesh, M., Mohtasebi, S. S., Ahmadi H. 2010. Predicting suitable workday and timeliness cost considering to reliability of machinery in Deabel Khazei sugarcane agroindustry, in proceeding of agricultural machinery and mechanization engineering. (In Farsi), 33-38.

Rahman, M. and Robson, A. 2016. A Novel Approach for Sugarcane Yield Prediction Using Landsat Time Series Imagery: A Case Study on Bundaberg Region. Advances in Remote Sensing, 5, 93-102. doi: 10.4236/ars.2016.52008.

Robson, A., Abbott, C., Lamb, D. and Bramley, R. 2012. Developing Sugar Cane Yield Prediction Algorithms from Satellite Imagery. Australian Society of Sugar Cane Technologists, 1-11.

Rouse, J.W., Haas, R.H., Schell, J.A., Deering, D.W. 1973. Monitoring Vegetation Systems in the Great Plains with ERTS. Third ERTS Symposium. 1, 309-317.

Shomeili, M. 2012. Evaluation of agricultural wastes produced during operation of sugarcane production. CD Proceedings of the 7th conference of Iranian sugar cane technologists. February 21-23. Iran, Ahvaz. (In Farsi), 643-649.

Tewari, J., Irudayaraj, J. 2003. Rapid Estimation of pol content in sugarcane juice using FTIR-ATR spectroscopy. Sugar Technology, 5(3), 143-148.

Valderrama, P.; Braga, J.; Poppi, R. 2007. Validation of multivariate calibration models in the determination of sugarcane quality parameters by near infrared spectroscopy. Journal of the Brazilian Chemical Society, 18(2), 259-266.

Zhao, Y., Justina, D. D., Kazama, Y., Rocha, J.V., Graziano, P. S. and Lamparelli, R. A. C. 2016. Dynamics modeling for sugar cane sucrose estimation using time series satellite imagery, Proc. SPIE 9998, Remote Sensing for Agriculture, Ecosystems, and Hydrology XVIII, 99980J. 